\title{
Sliding Mode Observers for Rotational Robotics Structures
}

\author{
Dorin Sendrescu, Dan Selişteanu, Emil Petre and Cosmin Ionete \\ Department of Automation and Mechatronics, University of Craiova \\ Romania
}

\section{Introduction}

The problem of controlling uncertain dynamical systems subject to external disturbances has been an issue of significant interest over the past several years. Most systems that we encounter in practice are subjected to various uncertainties such as nonlinearities, actuator faults parameter changes etc. Many of the proposed control strategies suppose that the state variables are available; this fact is not always true in practice, so the state vector must be estimated for use in the control laws. In the past, several types of observers have been designed for the reconstruction of state variables: Kalman filter (Kalman, 1976), adaptive observers (Gevers \& Bastin, 1986), high gain observers (Gauthier et al., 1992), sliding mode observers (SMO) (Utkin, 1992; Walcott \& Zak, 1986; Edwards \& Spurgeon, 1994) and so on see (Thein \& Misawa, 1995) for some comparisons. Depending upon the particular application, all these observers can be used with suitable results. Sliding mode observers differ from more traditional observers in that there is a non-linear discontinuous term injected into the observer depending on the output estimation error. These observers are known to be much more robust than Luenberger observers, as the discontinuous term enables the observer to reject disturbances (Tan \& Edwards, 2000). The observers based on the variable structure systems theory and sliding mode concept can be classified in two categories (Xiong \& Saif, 2000): 1) the equivalent control based methods and 2) sliding mode observers based on the method of Lyapunov. The analysis of these two types of SMO (Edwards \& Spurgeon, 1994; Xiong \& Saif, 2000) shows that there exist some differences in terms of robustness properties. From practical point of view, the selection of the switched gain for the equivalent control based SMO is difficult (in order to obtain a sliding mode without excessive chattering) (Edwards \& Spurgeon, 1994). Also, there exists bounded estimation error for bounded modelling errors (the estimation will not be accurate when uncertainties are presented) (Xiong \& Saif, 2000). The Lyapunov based SMO (the so-called Walcott-Zak observer) provides exact estimation for certain class of nonlinear systems under existence of certain class of uncertainties. However, the difficulty in finding the design and gain matrices is the main drawback of this observer. Consider the effect of adding a negative output feedback term to each equation of the Utkin observer. This results in a new error system. The addition of a Luenberger type gain matrix, feeding back the output error, yields the potential to provide robustness against certain classes of uncertainty. 
In order to test the performances of SMO, this work addresses the design and the implementation of SMO for two rotational Quanser experiments: flexible link and inverted pendulum experiments. Growing needs for advanced and precise robot manipulators in space industry and mechanically flexible constructions result in new and complicated problems of modelling, identification and control of flexible structures, i.e. flexible beams, robot arms, etc. Dealing with flexible systems one is faced with inherent infinite dimensionality of the systems, light damping, nonlinearities, influence of variable environment etc. One of the most important factors is to establish a suitable mathematical model of the system to make analysis as realistic as possible. Therefore, inclusion of the dynamics of electrical devices (i.e. DC servomotors, tachogenerators, etc.) to a mechanical model may be required. In recent years, various strategies were developed in order to control flexible beams: adaptive control, robust control (Gosavi \& Kelkar, 2001), different sliding-mode control strategies (Drakunov \& Ozguner, 1992; Jalili et al., 1997; Selisteanu et al., 2006), fuzzy control and some combined methods (Ionete, 2003; Gu \& Song, 2004). The control goal is to achieve the flexible link position control, and to damp the arm vibrations. In spite of the simplicity of the structure, an inverted pendulum system is a typical nonlinear dynamic control object, which includes a stable equilibrium point when the pendulum is at pending position and an unstable equilibrium point when the pendulum is at upright position. When the pendulum is raised from the pending position to the upright position, the inverted pendulum system is strongly nonlinear with the pendulum angle. The inverted pendulum is a classic problem in dynamics and control theory and widely used as benchmark for testing control algorithms (PID controllers, neural networks, genetic algorithms, etc). Variations on this problem include multiple links, allowing the motion of the cart to be commanded while maintaining the pendulum, and balancing the cartpendulum system on a see-saw. The inverted pendulum is related to rocket or missile guidance, where thrust is actuated at the bottom of a tall vehicle. The inverted pendulum exists in many different forms. The common thread among these systems is to balance a link on end using feedback control. In the rotary configuration, the first link, driven by a motor, rotates in the horizontal plane to balance a pendulum link, which rotates freely in the vertical plane. The real mathematical models of these systems are very complicated, so for control purpose simplified models are typically used. In general, the models of the rotational experiments are derived using Lagrange's energy equations, and consequently generalized dynamic equations are obtained. In order to obtain useful models for control design, approximations of these models can be derived (represented by nonlinear ordinary differential equations). Moreover, a linear approximation can be also obtained. Even the linear models have unknown or partially known parameters; therefore identification procedures are needed. The control strategies require the use of state variables; when the measurements of these states are not available, it is necessary to design a state observer.

The LQG/LTR (Linear Quadratic Gaussian/Loop Control Recovery) method is used in order to obtain feedback controllers for the benchmark Quanser experiments (Selisteanu et al., 2006). The aim of these controllers is to achieve robust stability margins and good performance in step response of the system. LQG/LTR method is a systematic design approach based on shaping and recovering open-loop singular values. Because the control laws necessitate the knowledge of state variables, the equivalent control method SMO and the modified Utkin SMO are designed and implemented. Some numerical simulations and real experiments are provided. 


\section{The models of quanser rotational experiments}

The Quanser experimental set-up contains the following components (Apkarian, 1997): Quanser Universal Power Module UPM 2405/1503; Quanser MultiQ PCI data acquisition board; Quanser Flexgage - Rotary Flexible Link Module; Quanser SRV02-E servo-plant; PC equipped with Matlab/Simulink and WinCon software.

WinCon $^{\mathrm{TM}}$ is a real-time Windows $98 / \mathrm{NT} / 2000 / \mathrm{XP}$ application. It allows running code generated from a Simulink diagram in real-time on the same PC (also known as local PC) or on a remote PC. Data from the real-time running code may be plotted on-line in WinCon Scopes and model parameters may be changed on the fly through WinCon Control Panels as well as Simulink. The automatically generated real-time code constitutes a stand-alone controller (i.e. independent from Simulink) and can be saved in WinCon Projects together with its corresponding user-configured scopes and control panels.

WinCon software actually consists of two distinct parts: WinCon Client and WinCon Server. WinCon Client runs in hard real-time while WinCon Server is a separate graphical interface, running in user mode. WinCon Server is the software component that performs the following functions: conversion of a Simulink diagram to $\mathrm{C}$ source code, starting and stopping the real-time code on WinCon Client, making changes to controller parameters using user-defined Control Panels and plotting the data streamed from the real-time code. WinCon supports two possible configurations: the local configuration (i.e. a single machine) and the remote configuration (i.e. two or more machines). In the local configuration, WinCon Client, executing the real-time code, runs on the same machine and at the same time as WinCon Server (i.e. the user-mode graphical interface). In the remote configuration, WinCon Client runs on a separate machine from WinCon Server. The two programs always communicate using the TCP/IP protocol. Each WinCon Server can communicate with several WinCon Clients, and reciprocally, each WinCon Client can communicate with several WinCon Servers. The local configuration was used to perform the real time experiments and is shown below in Fig. 1. The data acquisition card, in this case the MultiQ PCI, is used to interface the real-time code to the plant to be controlled. The user interacts with the real-time code via either WinCon Server or the Simulink diagram. Data from the running controller may be plotted in real-time on the WinCon scopes and changing values on the Simulink diagram automatically changes the corresponding parameters in the realtime code. The real-time code, i.e. WinCon Client, runs on the same PC. The real-time code takes precedence over everything else, so hard real-time performance is still achieved.

The PC running WinCon Server must have a compatible version of The MathWorks' MATLAB installed, in addition to Simulink, and the Real-Time Workshop toolbox.

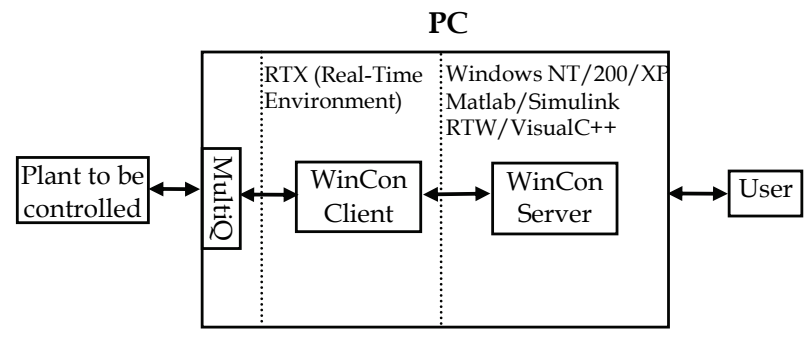

Fig. 1. The WinCon local configuration: WinCon Client and WinCon Server on same PC 


\section{A. Rotating Flexible Beam Model}

The rotary motion experiments are based on the Rotary Servo Plant SRV02-E. It consists of a DC servomotor with built in gearbox whose ratio is 70 to 1 . The output of the gearbox drives a potentiometer and an independent output shaft to which a load can be attached. The flexible link experiment consists of a mechanical and an electrical subsystem. The modelling of the mechanical subsystem consists in describing the tip deflection and the base rotation dynamics. The electrical subsystem involves modelling of DC servomotor that dynamically relates voltage to torque.

The Flexible Link module consists of a flat flexible arm at the end of which is a hinged potentiometer (Fig. 2). The flexible arm is mounted to the hinge. Measurement of the flexible arm deflection is obtained using a strain gage. The gage is calibrated to output 1 volt per 1 inch of tip deflection.

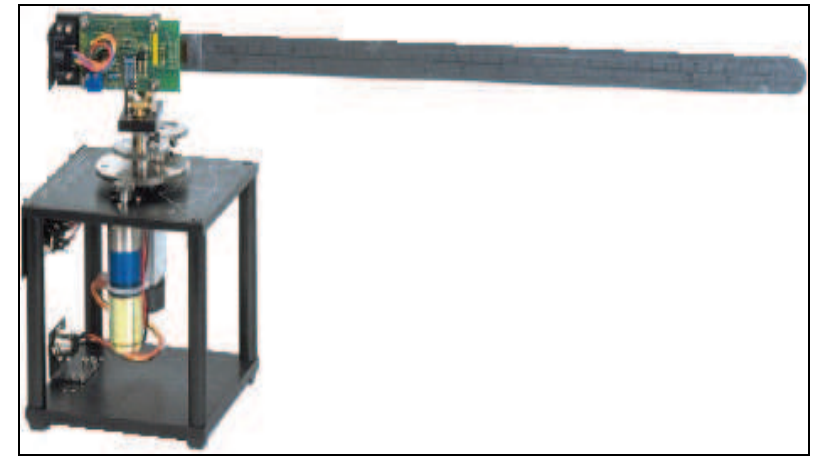

Fig. 2. Quanser Flexible Beam Experiment: SRV02-E servo plant and rotary flexible link module

The equations of motion involving a rotary flexible link imply modelling the rotational base and the flexible link as rigid bodies. As a simplification to the partial differential equation describing the motion of a flexible link, a lumped single degree of freedom approximation is used. We first start the derivation of the dynamic model by computing various rotational moment of inertia terms. The rotational inertia for a flexible link and a light source attachment is given respectively by

$$
\mathrm{J}_{\text {link }}=\frac{1}{3} \mathrm{~m}_{\text {link }} \mathrm{L}^{2}
$$

where $m_{\text {link }}$ is the total mass of the flexible link, and $\mathrm{L}$ is the total flexible link length. For a single degree of freedom system, the natural frequency is related with torsional stiffness and rotational inertia in the following manner

$$
\omega_{\mathrm{n}}=\sqrt{\frac{\mathrm{K}_{\text {stiff }}}{\mathrm{J}_{\text {link }}}}
$$

where $\omega_{\mathrm{n}}$ is found experimentally and $\mathrm{K}_{\mathrm{stiff}}$ is an equivalent torsion spring constant as delineated through the following figure 


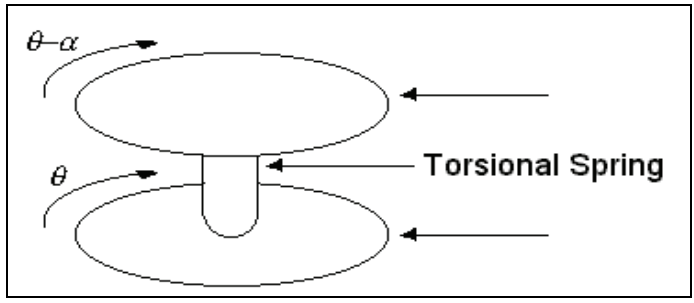

Fig. 3. Torsional spring

In addition, any frictional damping effects between the rotary base and the flexible link are assumed negligible. Next, we derive the generalized dynamic equation for the tip and base dynamics using Lagrange's energy equations in terms of a set of generalized variables $\alpha$ and $\theta$, where $\alpha$ is the angle of tip deflection and $\theta$ is the base rotation given in the following

$$
\begin{aligned}
& \frac{\partial}{\partial \mathrm{t}}\left(\frac{\partial \mathrm{T}}{\partial \dot{\theta}}\right)-\frac{\partial \mathrm{T}}{\partial \theta}+\frac{\partial \mathrm{P}}{\partial \theta}=\mathrm{Q}_{\theta} \\
& \frac{\partial}{\partial \mathrm{t}}\left(\frac{\partial \mathrm{T}}{\partial \dot{\alpha}}\right)-\frac{\partial \mathrm{T}}{\partial \alpha}+\frac{\partial \mathrm{P}}{\partial \alpha}=\mathrm{Q}_{\alpha}
\end{aligned}
$$

where $\mathrm{T}$ is the total kinetic energy of the system, $\mathrm{P}$ is the total potential energy of the system, and $Q_{i}$ is the ith generalized force within the ith degree of freedom. Kinetic energy of the base and the flexible link are given respectively as

$$
\begin{gathered}
\mathrm{T}_{\text {base }}=\frac{1}{2} \mathrm{~J}_{\text {base }} \dot{\theta}^{2} \\
\mathrm{~T}_{\text {link }}=\frac{1}{2} \mathrm{~J}_{\text {link }}(\dot{\theta}-\dot{\alpha})^{2}
\end{gathered}
$$

The total kinetic energy of the mechanical system is computed as the sum of (4) and (5)

$$
\mathrm{T}=\frac{1}{2} \mathrm{~J}_{\text {base }} \dot{\theta}^{2}+\frac{1}{2} \mathrm{~J}_{\text {link }}(\dot{\theta}-\dot{\alpha})^{2}
$$

Potential energy of the system provided by the torsional spring is given as

$$
P=\frac{1}{2} K_{\text {stiff }} \alpha^{2}
$$

Applying equation (6) and (7) into (3) results in the following dynamic equations

$$
\begin{aligned}
& \left(\mathrm{J}_{\text {base }}+\mathrm{J}_{\text {link }}\right) \ddot{\theta}-\mathrm{J}_{\text {link }} \ddot{\alpha}=Q_{\theta} \\
& -\mathrm{J}_{\text {link }} \ddot{\theta}+\mathrm{J}_{\text {link }} \ddot{\alpha}+\mathrm{K}_{\text {stiff }} \alpha=Q_{\alpha}
\end{aligned}
$$

Next we compute the amount of virtual work, W, applied into the system. The amount of virtual work is given to be 


$$
\delta \mathrm{W}=\tau \delta \theta+0 \delta \alpha
$$

where $\tau$ is the torque applied to the rotational base. Rewriting equation (9) into a general form of virtual work given as

$$
\delta \mathrm{W}=\mathrm{Q}_{\theta} \delta \theta+\mathrm{Q}_{\alpha} \delta \alpha
$$

one obtains the virtual forces applied onto the generalized coordinates $Q_{\theta}$ and $Q_{\alpha}$ respectively to be

$$
\mathrm{Q}_{\theta}=\tau, \mathrm{Q}_{\alpha}=0
$$

After decoupling the acceleration terms of (8), the dynamic equations for the mechanical subsystem are

$$
\begin{aligned}
& \ddot{\theta}=-\frac{\mathrm{K}_{\text {stiff }}}{\mathrm{J}_{\text {base }}} \alpha+\frac{1}{\mathrm{~J}_{\text {base }}} \tau ; \\
& \ddot{\alpha}=-\mathrm{K}_{\text {stiff }}\left(\frac{1}{\mathrm{~J}_{\text {link }}}+\frac{1}{\mathrm{~J}_{\text {base }}}\right) \alpha+\frac{1}{\mathrm{~J}_{\text {base }}} \tau
\end{aligned}
$$

Next, rewriting equations (12) into a state space form gives

$$
\left[\begin{array}{c}
\dot{\theta} \\
\dot{\alpha} \\
\ddot{\theta} \\
\ddot{\alpha}
\end{array}\right]=\left[\begin{array}{cccc}
0 & 0 & 1 & 0 \\
0 & 0 & 0 & 1 \\
0 & -\frac{\mathrm{K}_{\text {stiff }}}{\mathrm{J}_{\text {base }}} & 0 & 0 \\
0 & -\mathrm{K}_{\text {stiff }}\left(\frac{1}{\mathrm{~J}_{\text {link }}}+\frac{1}{\mathrm{~J}_{\text {base }}}\right) & 0 & 0
\end{array}\right]\left[\begin{array}{c}
\theta \\
\alpha \\
\dot{\theta} \\
\dot{\alpha}
\end{array}\right]+\left[\begin{array}{c}
0 \\
0 \\
\frac{1}{\mathrm{~J}_{\text {base }}} \\
\frac{1}{\mathrm{~J}_{\text {base }}}
\end{array}\right] \tau
$$

Since the control input into the mechanical model of equation (13) is a torque $\tau$, an electrical dynamic equation relating voltage to torque is needed.

First, the torque applied to the rotational base, on the right hand side of equation (13), is converted to the torque applied to the gear train by the DC servomotor by means of a gear ratio $K_{g}$ given as $\tau=K_{g} \tau_{m}$, where $\tau_{m}$ is the torque applied by the servomotor.

The DC servomotor is an electromechanical device that relates torque to current through a proportionality gain $\mathrm{K}_{\mathrm{T}}$. Applying Kirchoff's voltage law to the DC circuitry of the motor, and after some calculations, we obtain a state space model of (13), rewritten to utilize an electrical control voltage as input (Ionete, 2003):

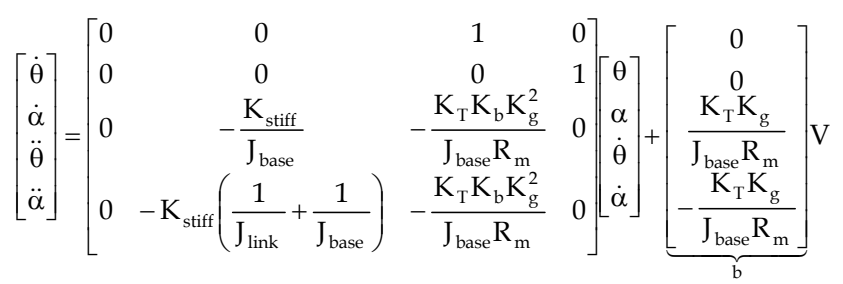


where $K_{b}$ is a proportional constant between angular velocity of the motor and the voltage applied by the motor shaft, $\mathrm{R}_{\mathrm{m}}$ is the resistance of the resistor of DC circuitry and V is the voltage supplied by the data acquisition board.

Next, a transformation between relative angular position and relative displacement about a neutral axis is used within the state space model. The relative angular position and the velocity with respect to the rotating base are proportional to the relative displacement and to the velocity of the flexible link tip (i.e. $\sin (\alpha) \approx \alpha$, for $\alpha$ small) respectively: $d=\alpha \cdot L$, $\dot{\mathrm{d}}=\dot{\alpha} \cdot \mathrm{L}$, where $\mathrm{d}$ is the relative displacement and $\mathrm{L}$ is the length of the flexible link. The Fig. 4 shows the relationship of these three parameters. Substituting the above equations into the state space dynamics previously obtained gives the following state space equation:

$$
\left[\begin{array}{c}
\dot{\theta} \\
\dot{\mathrm{d}} \\
\ddot{\theta} \\
\ddot{\mathrm{d}}
\end{array}\right]=\left[\begin{array}{cccc}
0 & 0 & 1 & 0 \\
0 & 0 & 0 & 1 \\
0 & -\frac{\mathrm{K}_{\text {stiff }}}{\mathrm{J}_{\text {base }} \mathrm{L}} & -\frac{\mathrm{K}_{\mathrm{T}} \mathrm{K}_{\mathrm{b}} \mathrm{K}_{\mathrm{g}}^{2}}{\mathrm{~J}_{\text {base }} \mathrm{R}_{\mathrm{m}}} & 0 \\
0 & -\frac{\mathrm{K}_{\text {stiff }}}{\mathrm{L}}\left(\frac{1}{\mathrm{~J}_{\text {link }}}+\frac{1}{\mathrm{~J}_{\text {base }}}\right) & -\frac{\mathrm{K}_{\mathrm{T}} \mathrm{K}_{\mathrm{b}} \mathrm{K}_{\mathrm{g}}^{2}}{\mathrm{~J}_{\text {base }} \mathrm{R}_{\mathrm{m}}} & 0
\end{array}\right]\left[\begin{array}{c}
\theta \\
\mathrm{d} \\
\dot{\theta} \\
\dot{\mathrm{d}}
\end{array}\right]+\mathrm{bV}
$$

The Quanser flexible beam parameters are: length of link: $L=0.45 \mathrm{~m}$; mass of link $\mathrm{m}=$ $0.0008 \mathrm{~kg}$; link inertia moment: $\mathrm{J}_{\text {link }}=0.0042 \mathrm{kgm}^{2}$; mass of base: $\mathrm{m}_{\mathrm{b}}=0.05 \mathrm{~kg}$; resistance of motor circuit: $\mathrm{R}_{\mathrm{m}}=2.6 \Omega$; gear ratio of rotary base: $\mathrm{K}_{\mathrm{g}}=70 / 1$; torque constant: $\mathrm{K}_{\mathrm{T}}=0.00767$ $\mathrm{Nm} / \mathrm{A}$; proportional constant: $\mathrm{K}_{\mathrm{b}}=0.00767 \mathrm{~V} /(\mathrm{rad} / \mathrm{sec})$; motor constant: $\mathrm{K}_{\mathrm{m}}=0.00767$ $\mathrm{Nm} / \mathrm{A}$; equivalent torsion spring constant: $\mathrm{K}_{\text {stiff }}=2 \mathrm{Nm} / \mathrm{rad}$; base inertia moment: Jbase $=$

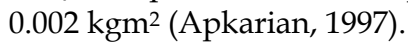

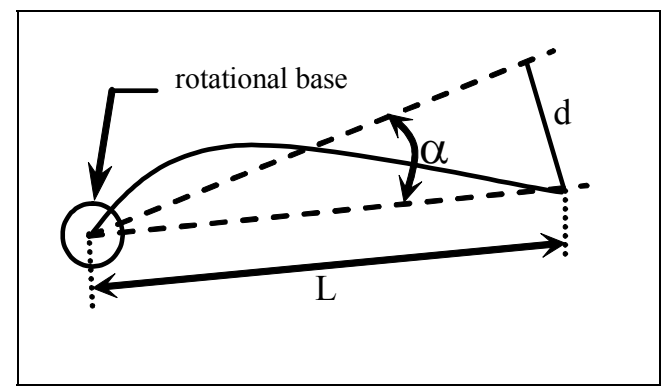

Fig. 4. Simplified model of flexible beam experiment

\section{B. Rotary Inverted Pendulum Model}

As a typical unstable nonlinear system, inverted pendulum system is often used as a benchmark for verifying the performance and effectiveness of a new control method because of the simplicity of the structure. Since the system has strong nonlinearity and inherent instability, it must to linearize the mathematical model of the object near upright position of the pendulum. To control both the angle of the pendulum and the position of the arm a robust controller will be tasted using a SMO to estimate the unmeasured states. The Quanser Rotary Inverted Pendulum module shown in Fig. 5.a consists of a rigid link (pendulum) rotating in a vertical plane. The rigid link is attached to a pivot arm, which is 
mounted on the load shaft of a DC-motor. The pivot arm can be rotated in the horizontal plane by the DC-motor. The DC-motor is instrumented with a potentiometer. In addition, a potentiometer is mounted on the pivot arm to measure the pendulum angle. The objective of the experiment is to design a control system that positions the arm as well as maintains the inverted pendulum vertical. This problem is similar to the classical inverted pendulum (linear) except that the trajectory is circular. The Quanser experimental set-up contains the following components: Quanser Universal Power Module UPM 2405/1503; Quanser MultiQ PCI data acquisition board; Quanser Rotary Inverted Pendulum; Quanser SRV02-E servoplant; PC equipped with Matlab/Simulink and WinCon software.

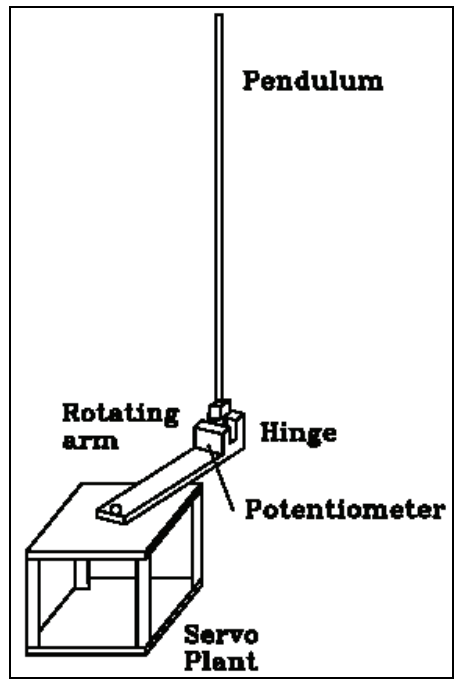

a)

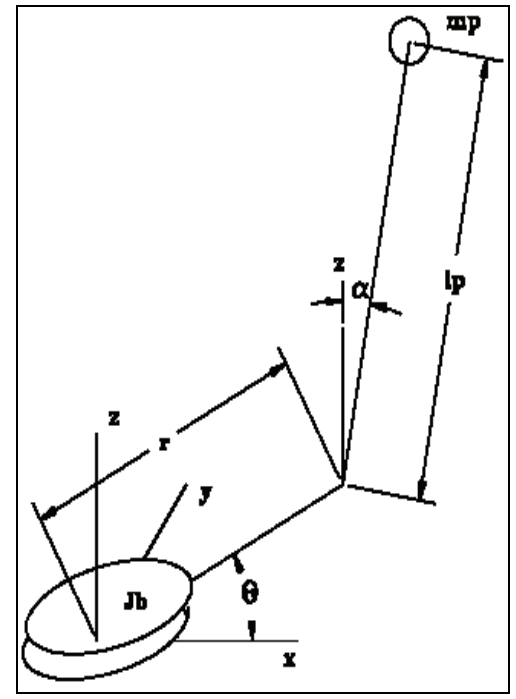

b)

Fig. 5. a) Schematic of Rotary Inverted Pendulum; b) Simplified model for rotary inverted pendulum

In order to obtain a useful model of the inverted pendulum, consider the simplified model in Fig. 5.b. Note that $l_{p}$ is half $L_{p}$, the actual length of the pendulum $\left(l_{p}=0.5 L_{p}\right)$. The kinetic and potential energies in the system are given by:

$$
\begin{aligned}
& \mathrm{P}_{\text {pen }}=\mathrm{m}_{\mathrm{p}} \mathrm{gl} \mathrm{p} \cos (\alpha) \\
& \mathrm{T}_{\text {pen }}=0.5 \mathrm{~m}_{\mathrm{p}}\left[\left(\dot{\theta} \mathrm{r}+\dot{\alpha} \mathrm{l}_{\mathrm{p}} \cos (\alpha)\right)^{2}+\left(\dot{\alpha} \mathrm{l}_{\mathrm{p}} \sin (\alpha)\right)^{2}\right] \\
& \mathrm{T}_{\text {base }}=0.5 \mathrm{~J}_{\mathrm{b}} \dot{\theta}^{2}
\end{aligned}
$$

where $\mathrm{T}$ is the kinetic energy of the system, $\mathrm{P}$ is the potential energy of the system. Using the above and the Lagrangian formulation one obtains the nonlinear differential equations of the system:

$$
\left\{\begin{array}{l}
\left(\mathrm{m}_{\mathrm{p}} \mathrm{r}^{2}+\mathrm{J}_{\mathrm{b}}\right) \ddot{\theta}+\mathrm{m}_{\mathrm{p}} \mathrm{r} \ddot{\alpha} \mathrm{l}_{\mathrm{p}} \cos (\alpha)-\mathrm{m}_{\mathrm{p}} \mathrm{r} \dot{\alpha}^{2} \mathrm{l}_{\mathrm{p}} \sin (\alpha)=\tau \\
\mathrm{m}_{\mathrm{p}} \mathrm{l}_{\mathrm{p}} \cos (\alpha) \ddot{\theta} \mathrm{r}-\mathrm{m}_{\mathrm{p}} \mathrm{l}_{\mathrm{p}} \sin (\alpha) \dot{\alpha} \dot{\theta} \mathrm{r}+\mathrm{m}_{\mathrm{p}} \ddot{\alpha} \mathrm{l}_{\mathrm{p}}^{2}-\mathrm{m}_{\mathrm{p}} \mathrm{gl} \mathrm{l}_{\mathrm{p}} \sin (\alpha)=0
\end{array}\right.
$$


where: $\tau$ is the input torque from motor $(\mathrm{Nm}), \mathrm{m}_{\mathrm{p}}$ the mass of rod $(\mathrm{kg}), \mathrm{l}_{\mathrm{p}}$ the centre of gravity of rod $(\mathrm{m}), \mathrm{J}_{\mathrm{b}}$ the inertia of arm and gears ( $\left.\mathrm{kgm}\right), \theta$ the deflection of arm from zero position ( $\mathrm{rad}$ ), $\alpha$ the deflection of pendulum from vertical up position ( $\mathrm{rad}$ ).

The linear equations resulting from (17) are:

$$
\left[\begin{array}{c}
\dot{\theta} \\
\dot{\alpha} \\
\ddot{\theta} \\
\ddot{\alpha}
\end{array}\right]=\left[\begin{array}{cccc}
0 & 0 & 1 & 0 \\
0 & 0 & 0 & 1 \\
0 & -\frac{\mathrm{m}_{\mathrm{p}} \mathrm{rg}}{\mathrm{J}_{\mathrm{b}}} & 0 & 0 \\
0 & \mathrm{~g} \frac{\mathrm{J}_{\mathrm{b}}+\mathrm{m}_{\mathrm{p}} \mathrm{r}^{2}}{\mathrm{l}_{\mathrm{p}} \mathrm{J}_{\mathrm{b}}} & 0 & 0
\end{array}\right]\left[\begin{array}{c}
\theta \\
\alpha \\
\dot{\theta} \\
\dot{\alpha}
\end{array}\right]+\left[\begin{array}{c}
0 \\
0 \\
\frac{1}{\mathrm{~J}_{\mathrm{b}}} \\
-\frac{\mathrm{r}}{\mathrm{l}_{\mathrm{p}} \mathrm{J}_{\mathrm{b}}}
\end{array}\right] \tau
$$

Note that the zero position for all the above equations is defined as the pendulum being vertical "up". The motor equations are:

$$
\mathrm{V}=\mathrm{I}_{\mathrm{m}} \mathrm{R}_{\mathrm{m}}+\mathrm{K}_{\mathrm{m}} \mathrm{K}_{\mathrm{g}} \dot{\theta}
$$

where: $\mathrm{V}$ (volts) is the voltage applied to motor, $\mathrm{I}_{\mathrm{m}}(\mathrm{amp})$ is the current in motor, $\mathrm{K}_{\mathrm{m}}$ $(\mathrm{V} /(\mathrm{rad} \cdot \mathrm{sec}))$ the back EMF constant, $\mathrm{K}_{\mathrm{g}}$ the gear ratio in motor gearbox and external gears.

The torque generated by the motor is: $\tau=\mathrm{K}_{\mathrm{m}} \mathrm{K}_{\mathrm{g}} \mathrm{I}_{\mathrm{m}}=\mathrm{J}_{\mathrm{b}} \ddot{\theta}$. We have also $\frac{\theta(\mathrm{s})}{\mathrm{V}(\mathrm{s})}=1 / \mathrm{s}\left(\frac{\mathrm{J}_{\mathrm{b}} \mathrm{R}_{\mathrm{m}}}{\mathrm{K}_{\mathrm{m}} \mathrm{K}_{\mathrm{g}}} \mathrm{s}+\mathrm{K}_{\mathrm{m}} \mathrm{K}_{\mathrm{g}}\right)$, where $\mathrm{s}$ is the complex variable from Laplace transform.

The linear model that was developed is based on a torque $\tau$ applied to the arm. The actual system however is voltage driven. From the motor equations derived above one get that $\tau=\mathrm{V} \frac{\mathrm{K}_{\mathrm{m}} \mathrm{K}_{\mathrm{g}}}{\mathrm{R}_{\mathrm{m}}}-\frac{\mathrm{K}_{\mathrm{m}}{ }^{2} \mathrm{~K}_{\mathrm{g}}{ }^{2}}{\mathrm{R}_{\mathrm{m}}} \dot{\theta}$. Finally, one obtains the following linear model:

$$
\left[\begin{array}{c}
\dot{\theta} \\
\dot{\alpha} \\
\ddot{\theta} \\
\ddot{\alpha}
\end{array}\right]=\left[\begin{array}{cccc}
0 & 0 & 1 & 0 \\
0 & 0 & 0 & 1 \\
0 & -\frac{\mathrm{m}_{\mathrm{p}} \mathrm{rg}}{\mathrm{J}_{\mathrm{b}}} & -\frac{\mathrm{K}_{\mathrm{m}}^{2} \mathrm{~K}_{\mathrm{g}}^{2}}{\mathrm{~J}_{\mathrm{b}} \mathrm{R}_{\mathrm{m}}} & 0 \\
0 & \mathrm{~g} \frac{\mathrm{J}_{\mathrm{b}}+\mathrm{m}_{\mathrm{p}} \mathrm{r}^{2}}{\mathrm{l}_{\mathrm{p}} \mathrm{J}_{\mathrm{b}}} & \frac{\mathrm{rK}_{\mathrm{m}}^{2} \mathrm{~K}_{\mathrm{g}}^{2}}{\mathrm{l}_{\mathrm{p}} \mathrm{J}_{\mathrm{b}} \mathrm{R}_{\mathrm{m}}} & 0
\end{array}\right]\left[\begin{array}{c}
\theta \\
\alpha \\
\dot{\theta} \\
\dot{\alpha}
\end{array}\right]+\left[\begin{array}{c}
0 \\
0 \\
\frac{\mathrm{K}_{\mathrm{m}} \mathrm{K}_{\mathrm{g}}}{\mathrm{J}_{\mathrm{b}} \mathrm{R}_{\mathrm{m}}} \\
-\frac{\mathrm{rK}_{\mathrm{m}} \mathrm{K}_{\mathrm{g}}}{\mathrm{l}_{\mathrm{p}} \mathrm{J}_{\mathrm{b}} \mathrm{R}_{\mathrm{m}}}
\end{array}\right] \mathrm{V}
$$

The Quanser inverted pendulum parameters are: pendulum length: $L=21_{p}=0.305 \mathrm{~m}$; arm length $\mathrm{r}=0.145 \mathrm{~m}$; mass of pendulum $\mathrm{m}_{\mathrm{p}}=0.105 \mathrm{~kg}$; resistance of motor circuit: $\mathrm{R}_{\mathrm{m}}=2.6 \Omega$; back EMF constant: $\mathrm{K}_{\mathrm{m}}=0.00767 \mathrm{~V} /(\mathrm{rad} / \mathrm{sec})$; external gear ratio: $\mathrm{K}_{\mathrm{g}}=70: 1$; base inertia moment: $\mathrm{J}_{\mathrm{b}}=0.0044 \mathrm{kgm}^{2}$. 


\section{LQG/LTR control strategy}

Nonlinear system model imprecision may come from actual uncertainty about the plant (e.g., unknown plant parameters), or from the purposeful choice of a simplified representation of the system's dynamics. Modeling inaccuracies can be classified into two major kinds: structured (or parametric) uncertainties and unstructured uncertainties (or unmodeled dynamics). The first kind corresponds to inaccuracies on the terms actually included in the model, while the second kind corresponds to inaccuracies on the system order. Modeling inaccuracies can have strong adverse effects on nonlinear control systems. One of the most important approaches to dealing with model uncertainty is robust control. The LQG/LTR (Linear Quadratic Gaussian/Loop Control Recovery) theory is a powerful method for the control of linear systems in the state-space domain (Athans, 1986). The aim of these controllers is to achieve robust stability margins and good performance in step response of the system. LQG/LTR method is a systematic design approach based on shaping and recovering open-loop singular values. This LQG/LTR technique generates controllers with guaranteed closed loop stability robustness property even in the face of certain gain and phase variation at the plant input/output. In addition, the LQG/LTR controllers provide reliable closed-loop system performance despite of stochastic plant disturbance. The LQ control design framework is applicable to the class of stabilizable linear systems. Briefly, the LQG/LTR theory says that, given a $\mathrm{n}^{\text {th }}$ order stabilizable system

$$
\dot{x}(t)=A x(t)+B u(t), t \geq 0, x(0)=x_{0}
$$

where $\mathrm{x}(\mathrm{t}) \in \mathfrak{R}^{\mathrm{n}}$ is the state vector and $\mathrm{u}(\mathrm{t}) \in \mathfrak{R}^{\mathrm{m}}$ is the input vector, determine the matrix gain $K \in \mathfrak{R}^{\mathrm{mxn}}$ such that the static, full-state feedback control law $u(t)=-K x(t)$ satisfies the following criteria

1) The closed loop state space system is asymptotically stable;

2) The performance functional given by

$$
\mathrm{J}(\mathrm{K}) \stackrel{\Delta}{\Delta} \int_{0}^{\infty}\left[\mathrm{x}^{\mathrm{T}}(\mathrm{t}) \mathrm{Qx}(\mathrm{t})+\mathrm{u}^{\mathrm{T}}(\mathrm{t}) \mathrm{Ru}(\mathrm{t})\right] \mathrm{dt}
$$

is minimized.

The performance functional of equation (22) regulates the state trajectories of $x$ close to the origin without excessive control demand through the design of the penalty weights of nonnegative definite matrices $Q$ and $R$. The solution of the LQG/LTR problem can be obtained via a Lagrange multiplier-based optimisation technique and is given by $K=R^{-1} B^{T} P$, where $P \in \Re^{n \times n}$ is a nonnegative-definite matrix satisfying the following algebraic Riccati equation

$$
\mathrm{A}^{\mathrm{T}} \mathrm{P}+\mathrm{PA}+\mathrm{Q}-\mathrm{PBR}^{-1} \mathrm{~B}^{\mathrm{T}} \mathrm{P}=0
$$

Note that it follows that the LQG/LTR-based control design requires the availability of all state variables for feedback purpose. 
LQG/LTR strategy for the flexible beam. The objective for the rotary flexible link dynamic system is to achieve an asymptotically stable system response for flexible link. For the state variable of $d(t)$ in (15), a LQG/LTR based controller drives the flexible dynamic response to zero asymptotically. For tracking the angular position, a new state variable is required to allow setpoint tracking. To achieve error regulation, an angular error and an angular velocity error are defined respectively as

$$
\mathrm{e}(\mathrm{t}) \stackrel{\Delta}{=} \theta(\mathrm{t})-\theta_{\mathrm{d}}, \dot{\mathrm{e}}(\mathrm{t})=\dot{\theta}(\mathrm{t})
$$

where $\theta_{\mathrm{d}}$ is a desired constant angular position for the flexible link. In addition, an integral controller coupled in the rigid body dynamics is defined within the state space dynamics of (15), $\dot{\phi}(\mathrm{t})=\mathrm{e}(\mathrm{t})$, so that the state space dynamics is augmented to give the final linear model. The under-actuated control objective involves error regulation for the absolute angular displacement of the rotary base and vibration control for the end of the flexible link. Using the above-described LQG/LTR controller design method and the model of the plant obtained with the identification procedure, we are able to get the state-feedback vector. For the Quanser flexible beam, the arm angle and the deflection are measured by a potentiometer and a strain gage respectively. Any physical sensor does not measure the flexible arm angular velocity and the deflection velocity; instead we compute these velocities using a modified Utkin sliding mode observer as a part of overall control scheme. The LQG/LTR strategy ensures a good behaviour with respect to angular reference tracking and has a good perturbation rejection capability.

$L Q R$ strategy for the inverted pendulum. The state variables used for the control experiment are $\mathrm{x}(\mathrm{t})=\left[\begin{array}{llll}\theta(\mathrm{t}) & \alpha(\mathrm{t}) & \dot{\theta}(\mathrm{t}) & \dot{\alpha}(\mathrm{t})\end{array}\right]^{\mathrm{T}}$. For our laboratory model, the pivot arm angle $\theta$ and the pendulum angular position $\alpha$ are measured by two potentiometers. The pivot arm angular velocity $\dot{\theta}$ and pendulum angular velocity $\dot{\alpha}$ are not measured by any physical sensor, instead, we numerically compute $\dot{\theta}$ and $\dot{\alpha}$ by implementing a modified Utkin sliding mode observer. In order to regulate precisely the pendulum position, we introduce another state, the integral of the rotary arm error. So the state vector becomes: $x(t)=\left[\theta(t), \alpha(t), \dot{\theta}(t), \dot{\alpha}(t), \int \theta(t) d t\right]^{T}$. Then, the above described LQG/LTR strategy can be successfully applied.

\section{Design of the sliding mode observers}

\section{A. Utkin sliding-mode observer}

The sliding mode technique has been widely studied and developed for the control and state estimation problems since the works of Utkin. Observers based on sliding mode approach first were developed for linear systems (Jalili et al., 1997). Consider the following linear time-invariant system:

$$
\left\{\begin{array}{l}
\dot{x}=A x+B u \\
y=C x
\end{array} \quad A \in \Re^{n \times n}, B \in \Re^{n \times p}, C \in \Re^{p \times n}\right.
$$


The problem to be considered is that of reconstructing the state variables using only measured output information. Without loss of generality we assume that $\operatorname{rank} C=p$. It is also assume that the pair $\{C, A\}$ is observable and matrices $A, B, C$ are known. In this case, the observed vector y may be represented as:

$$
\begin{aligned}
& y=C_{a} x_{a}+C_{b} x_{b}, x=\left(x_{a}, x_{b}\right), \\
& C_{a} \in \Re^{p \times(n-p)}, C_{b} \in \Re^{p \times p}, \operatorname{det}\left(C_{b}\right) \neq 0
\end{aligned}
$$

Using the following linear transformation of state variable:

$$
\mathrm{T}_{1}=\left[\begin{array}{cc}
\mathrm{I}_{\mathrm{n}-\mathrm{p}} & 0 \\
\mathrm{C}_{\mathrm{a}} & \mathrm{C}_{\mathrm{b}}
\end{array}\right]
$$

the system described by (25) can be written in the form:

$$
\begin{aligned}
& \dot{\mathrm{x}}_{\mathrm{a}}=\mathrm{A}_{11} \mathrm{x}_{\mathrm{a}}+\mathrm{A}_{12} \mathrm{y}+\mathrm{B}_{1} \mathrm{u} \\
& \dot{\mathrm{y}}=\mathrm{A}_{21} \mathrm{x}_{\mathrm{a}}+\mathrm{A}_{22} \mathrm{y}+\mathrm{B}_{2} \mathrm{u}
\end{aligned}
$$

The corresponding sliding mode observer proposed by Utkin is given by:

$$
\left\{\begin{array}{l}
\dot{\hat{x}}_{a}=A_{11} \hat{x}_{a}+A_{12} \hat{y}+B_{1} u+\operatorname{LMsgn}(\hat{y}-y) \\
\dot{\hat{y}}=A_{22} \hat{y}+A_{21} \hat{x}_{a}+B_{2} u-M \operatorname{sgn}(\hat{y}-y)
\end{array}\right.
$$

where $\left(\hat{x}_{a}, \hat{y}\right)$ are the estimates for $\left(x_{a}, y\right), L \in \Re^{(n-p) \times p}$ is a constant nonsingular feedback gain matrix and sgn is the signum function and $M$ is a strictly positive gain. If one define $\varepsilon_{\mathrm{y}}=\hat{\mathrm{y}}-\mathrm{y}$ and $\varepsilon_{\mathrm{a}}=\hat{\mathrm{x}}_{\mathrm{a}}-\mathrm{x}_{\mathrm{a}}$ then, the following error system is obtained

$$
\left\{\begin{array}{l}
\dot{\varepsilon}_{\mathrm{a}}=\mathrm{A}_{11} \varepsilon_{\mathrm{a}}+\mathrm{A}_{12} \varepsilon_{\mathrm{y}}+\operatorname{LMsgn}\left(\varepsilon_{\mathrm{y}}\right) \\
\dot{\varepsilon}_{\mathrm{y}}=\mathrm{A}_{21} \varepsilon_{\mathrm{a}}+\mathrm{A}_{22} \varepsilon_{\mathrm{y}}-\operatorname{Msgn}\left(\varepsilon_{\mathrm{y}}\right)
\end{array}\right.
$$

Defining the following change of coordinates:

$$
\mathrm{T}_{2}=\left[\begin{array}{cc}
\mathrm{I}_{\mathrm{n}-\mathrm{p}} & \mathrm{L} \\
0 & \mathrm{I}_{\mathrm{p}}
\end{array}\right]
$$

then the error system with respect to these new coordinates can be written as:

$$
\begin{gathered}
\dot{\widetilde{\varepsilon}}_{\mathrm{a}}=\widetilde{\mathrm{A}}_{11} \widetilde{\varepsilon}_{\mathrm{a}}+\widetilde{\mathrm{A}}_{12} \varepsilon_{\mathrm{y}} \\
\dot{\varepsilon}_{\mathrm{y}}=\mathrm{A}_{21} \widetilde{\varepsilon}_{\mathrm{a}}+\widetilde{\mathrm{A}}_{22} \varepsilon_{\mathrm{y}}-\operatorname{Msgn}\left(\varepsilon_{\mathrm{y}}\right)
\end{gathered}
$$

where:

$$
\begin{aligned}
& \widetilde{\mathrm{A}}_{11}=\mathrm{A}_{11}+\mathrm{LA}_{21} ; \widetilde{\mathrm{A}}_{12}=\mathrm{A}_{12}+\mathrm{LA}_{22}-\widetilde{\mathrm{A}}_{11} \mathrm{~L} ; \\
& \widetilde{\mathrm{A}}_{22}=\mathrm{A}_{22}-\mathrm{A}_{21} \mathrm{~L}
\end{aligned}
$$


It can be shown that for large enough $\mathrm{M}>0$ a sliding mode motion can be induced on the output error state in (33). It follows that, after some finite time $\varepsilon_{\mathrm{y}}=0$ and $\dot{\varepsilon}_{\mathrm{y}}=0$. Equation (32) then reduces to

$$
\dot{\widetilde{\varepsilon}}_{\mathrm{a}}=\widetilde{\mathrm{A}}_{11} \widetilde{\varepsilon}_{\mathrm{a}}
$$

which by choice of $L$ represents a stable system and so $\widetilde{\varepsilon}_{a} \rightarrow 0$ as $t \rightarrow \infty$. Consequently $\hat{x}_{a} \rightarrow x_{a}$ and the remaining states can be constructed in the original coordinate system as

$$
\hat{\mathrm{x}}_{\mathrm{b}}=\mathrm{C}_{\mathrm{b}}^{-1}\left(\mathrm{y}-\mathrm{C}_{\mathrm{a}} \hat{\mathrm{x}}_{\mathrm{a}}\right)
$$

\section{B. Modified Utkin sliding-mode observer}

The major practical difficulty in the approach presented in subsection A is the selection of an appropriate gain $\mathrm{M}$ to induce a sliding motion in finite time (Edwards \& Spurgeon, 1994). Consider the effect of adding a negative output error feedback term to each equation of the Utkin observer (29) (Xiong \& Saif, 2000). This results in a new error system governed by:

$$
\left\{\begin{array}{l}
\dot{\widetilde{\varepsilon}}_{\mathrm{a}}=\widetilde{\mathrm{A}}_{11} \widetilde{\varepsilon}_{\mathrm{a}}+\widetilde{\mathrm{A}}_{12} \varepsilon_{\mathrm{y}}-\mathrm{G}_{1} \varepsilon_{\mathrm{y}} \\
\dot{\varepsilon}_{\mathrm{y}}=\mathrm{A}_{21} \widetilde{\varepsilon}_{\mathrm{a}}+\widetilde{\mathrm{A}}_{22} \varepsilon_{\mathrm{y}}-\mathrm{G}_{2} \varepsilon_{\mathrm{y}}-\operatorname{Msgn}\left(\varepsilon_{\mathrm{y}}\right)
\end{array}\right.
$$

By selecting $G_{1}=\widetilde{A}_{12}$ and $G_{2}=\widetilde{A}_{22}-A_{22}^{s}$ where $A_{22}^{s}$ is any stable design matrix of appropriate dimension, then

$$
\left\{\begin{array}{l}
\dot{\tilde{\varepsilon}}_{\mathrm{a}}=\widetilde{\mathrm{A}}_{11} \widetilde{\varepsilon}_{\mathrm{a}} \\
\dot{\varepsilon}_{\mathrm{y}}=\mathrm{A}_{21} \widetilde{\varepsilon}_{\mathrm{a}}+\mathrm{A}_{22}^{\mathrm{s}} \varepsilon_{\mathrm{y}}-\operatorname{Msgn}\left(\varepsilon_{\mathrm{y}}\right)
\end{array}\right.
$$

In this form the (nominal) error system is asymptotically stable for any $\operatorname{Msgn}\left(\varepsilon_{\mathrm{y}}\right)$ because the poles of the combined system are given by $\sigma\left(\tilde{\mathrm{A}}_{11}\right) \cup \sigma\left(\mathrm{A}_{22}^{\mathrm{s}}\right)$ and so lie in the open left half complex plane. The two gain matrices $G_{1}$ and $G_{2}$ yields the potential to provide robustness against certain classes of uncertainty.

As it can be seen from relations (15) and (20), the system matrices for flexible link and inverted pendulum models have a similar structure of the following form:

$$
A=\left[\begin{array}{cccc}
0 & 0 & 1 & 0 \\
0 & 0 & 0 & 1 \\
0 & a_{32} & a_{33} & 0 \\
0 & a_{42} & a_{43} & 0
\end{array}\right], B=\left[\begin{array}{c}
0 \\
0 \\
b_{3} \\
b_{4}
\end{array}\right], C=\left[\begin{array}{llll}
c_{1} & c_{2} & 0 & 0
\end{array}\right], D=0
$$

Choosing $\mathrm{C}_{\mathrm{a}}=\left[\begin{array}{lll}0 & 0 & \mathrm{c}_{2}\end{array}\right], \mathrm{C}_{\mathrm{b}}=\mathrm{c}_{1}$ and using the linear transformation:

$$
\mathrm{T}_{1}=\left[\begin{array}{cccc}
1 & 0 & 0 & 0 \\
0 & 1 & 0 & 0 \\
0 & 0 & 1 & 0 \\
0 & 0 & \mathrm{c}_{2} & \mathrm{c}_{1}
\end{array}\right]
$$


the matrices from (28) has the following form:

$$
\mathrm{A}_{11}=\left[\begin{array}{ccc}
0 & \mathrm{a}_{43} & \mathrm{a}_{42} \\
0 & \mathrm{a}_{33} & \mathrm{a}_{32} \\
1 & 0 & 0
\end{array}\right], \mathrm{A}_{12}=\left[\begin{array}{l}
0 \\
0 \\
0
\end{array}\right], \mathrm{A}_{21}=\left[\begin{array}{lll}
\mathrm{c}_{2} & \mathrm{c}_{1} & 0
\end{array}\right], \mathrm{A}_{22}=0 \quad \mathrm{~B}_{1}=\left[\begin{array}{c}
\mathrm{b}_{4} \\
\mathrm{~b}_{3} \\
0
\end{array}\right], \mathrm{B}_{2}=0
$$

and the matrices for the modified Utkin sliding-mode observer are:

$$
\begin{gathered}
\mathrm{G}_{1}=\mathrm{A}_{12}+\mathrm{LA}_{22}-\mathrm{A}_{11} \mathrm{~L}-\mathrm{LA} \mathrm{A}_{21} \mathrm{~L} \\
\mathrm{G}_{2}=\mathrm{A}_{22}-\mathrm{A}_{22} \mathrm{~L}-\mathrm{A}_{22}^{\mathrm{s}}
\end{gathered}
$$

i) Numerical values for the Flexible Beam case

For the flexible beam experiment we have the following numerical values for the parameters:

$$
\begin{gathered}
\mathrm{a}_{32}=-2035.9 ; \mathrm{a}_{33}=-55.435 ; \mathrm{a}_{42}=-2320.1 ; \mathrm{a}_{43}=-55.435 ; \\
\mathrm{b}_{3}=103.25 ; \mathrm{b}_{4}=-103.25 \\
\mathrm{G}_{1}=\left[\begin{array}{c}
-237.59 \\
-209.16 \\
0.067
\end{array}\right] \quad \mathrm{G}_{2}=-0.677
\end{gathered}
$$

ii) Numerical values for the Inverted Pendulum case

For the inverted pendulum experiment we have the following numerical values for the parameters:

$$
\begin{gathered}
\mathrm{a}_{32}=-33.95 ; \mathrm{a}_{33}=-25.19 ; \mathrm{a}_{42}=96.60 ; \mathrm{a}_{43}=23.96 ; \\
\mathrm{b}_{3}=46.93 ; \mathrm{b}_{4}=-44.62 \\
\mathrm{G}_{1}=\left[\begin{array}{c}
585.6 \\
-1065.6 \\
-195
\end{array}\right] \quad \mathrm{G}_{2}=29
\end{gathered}
$$

\section{Experimental results}

\section{A. Flexible beam case}

The objective for the rotary flexible link dynamic system is to achieve an asymptotically stable system response for flexible link. This system is very sensitive to derivative feedback gains because the unmodelled higher modes will be excited if the bandwidth of the system is too high or if high frequency noise is present. Using the LQG/LTR design described in the previous section we obtain the optimal feedback gain $\mathrm{K}$ for the feedback law with the following components:

$$
\mathrm{k}_{1}=0.025 ; \mathrm{k}_{2}=-0.6 ; \mathrm{k}_{3}=0.005 ; \mathrm{k}_{4}=0.01
$$


The experimental results obtained to step reference for feedback gain matrix $\mathrm{L}=[-0.1 ;-0.1 ;-0.1]$ and $\mathrm{M}=5$ are presented in Fig. 6 :

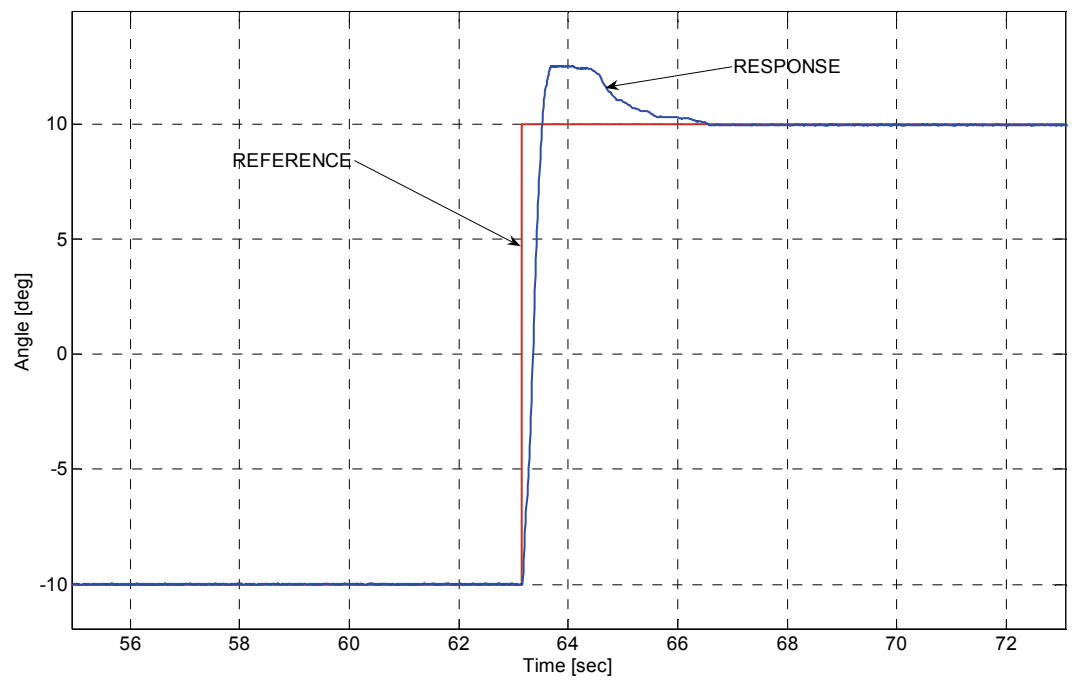

Fig. 6. Experimental step response of flexible link

In Fig. 7 the evolution of one measured state (arm angle velocity) and of its estimation is presented and in Fig. 8 the real and estimated arm angle evolution are depicted and it can be seen the good convergence of the sliding mode observer.

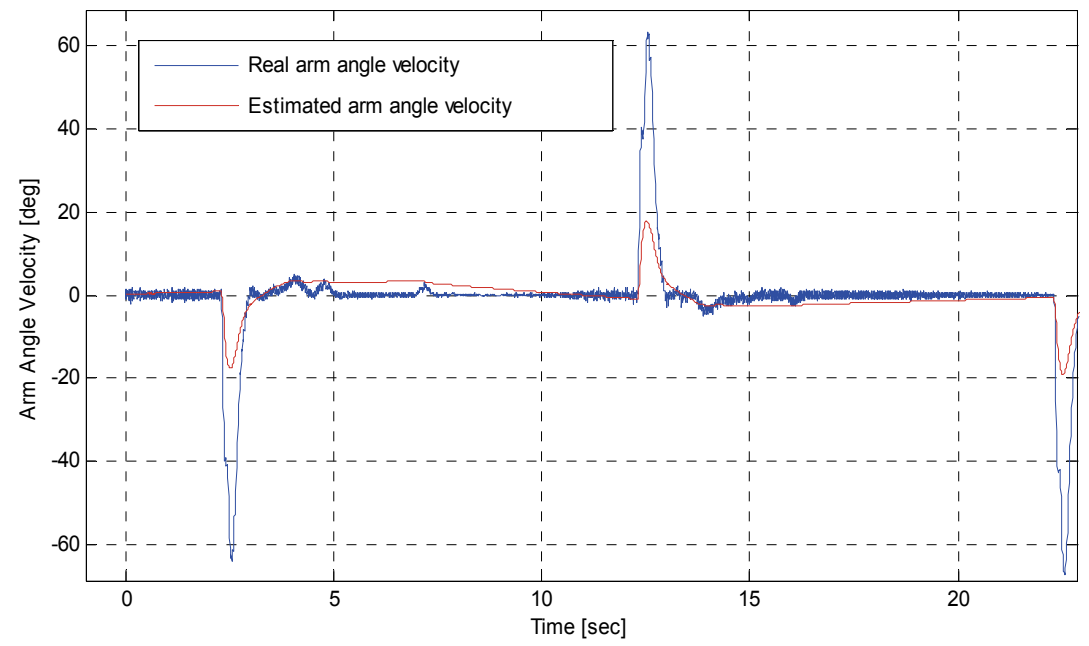

Fig. 7. Real and estimated arm angle velocity for flexible beam experiment 


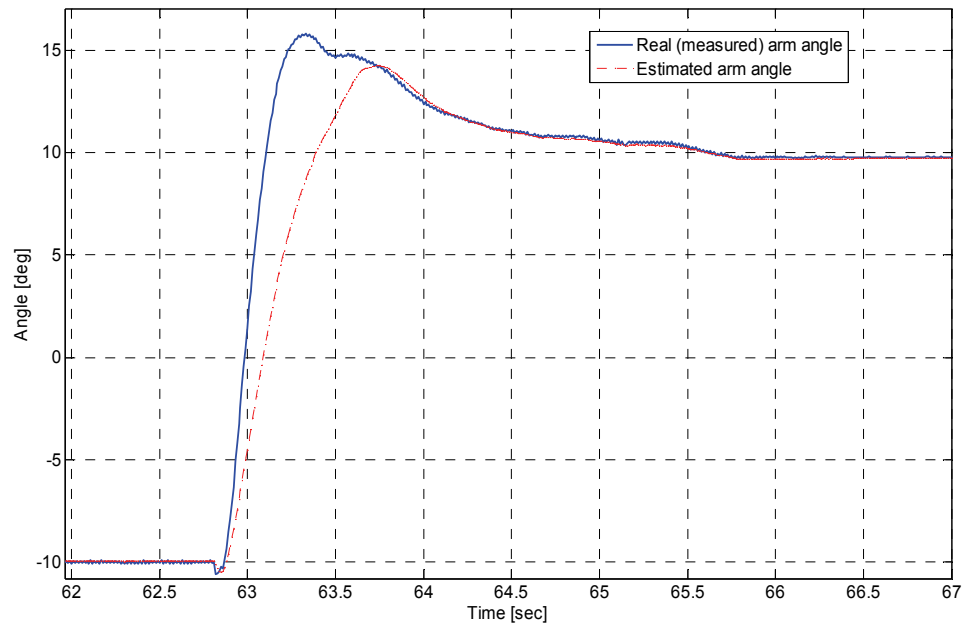

Fig. 8. Real and estimated arm angle for flexible beam experiment

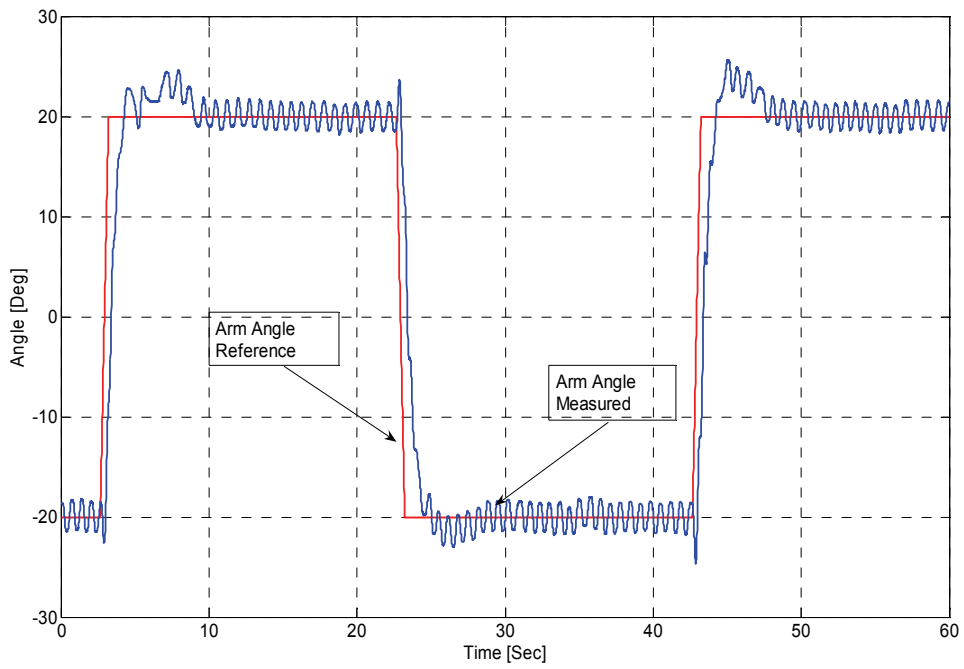

Fig. 9. Step response for real inverted pendulum experiment

\section{B. Inverted pendulum case}

The objective of the experiment is to design a control system that positions the arm as well as maintains the inverted pendulum vertical. The robust controller will be tested using a SMO to estimate the unmeasured states. Using the LQG/LTR design we obtain the optimal feedback gain $\mathrm{K}$ for the feedback law:

$$
\mathrm{k}_{1}=-0.09 ; \mathrm{k}_{2}=-0.9 ; \mathrm{k}_{3}=-0.08 ; \mathrm{k}_{4}=-0.1
$$


The experimental results obtained to step references for feedback gain matrix $\mathrm{L}=[-10 ;-10 ;-5]$ and $\mathrm{M}=20$ are presented in Fig. 9 .

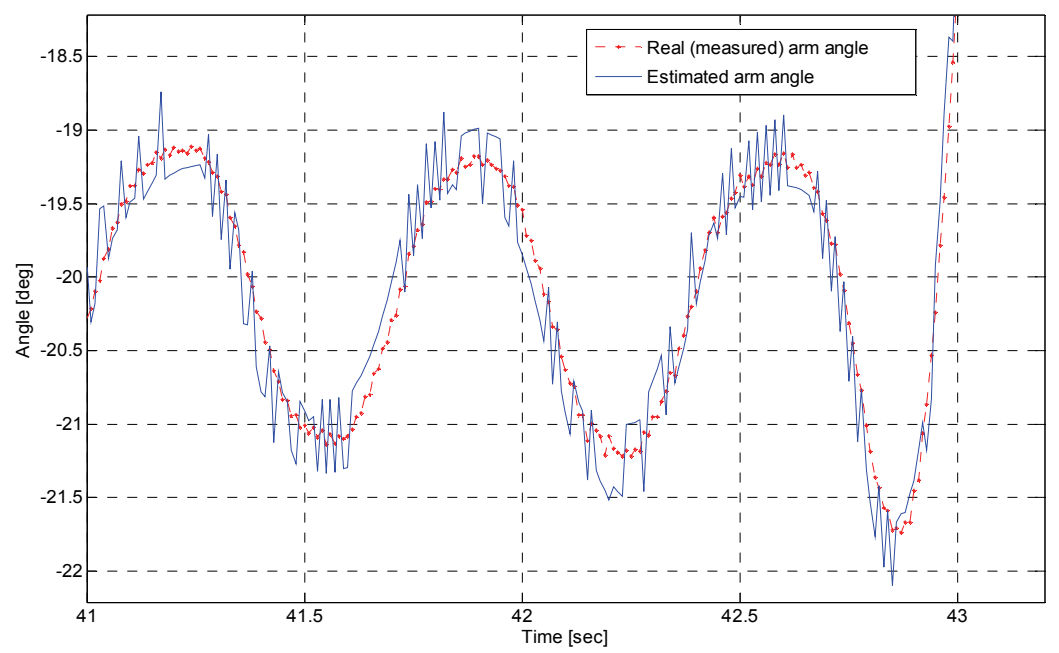

Fig. 10. Real and estimated arm angle for real inverted pendulum experiment

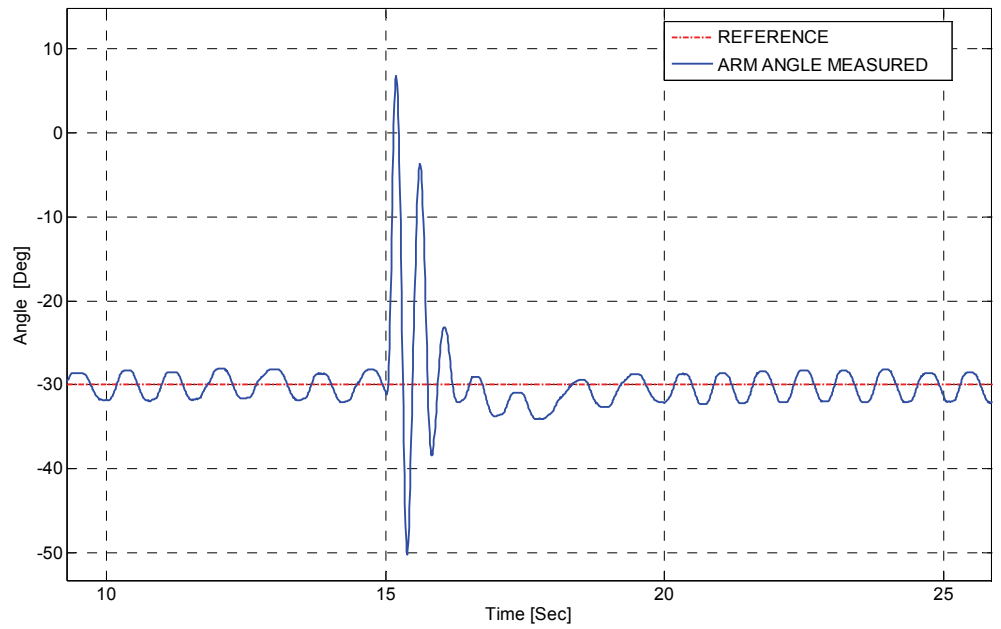

Fig. 11. The behaviour of the perturbed inverted pendulum

In Fig. 10 is presented the real and estimated arm angle evolution for the inverted pendulum system. It can be seen the small chattering due to the sliding mode estimations. In Fig. 11 the disturbance response of pendulum to a tap is presented. The pendulum is tapped such that it falls around 30 degree which causes the arm to move towards the falling direction. This results in the pendulum swinging to about 20 degree in the opposite direction. The system 
recovers in about 4 seconds. Advantages demonstrated by the SMO techniques for the inverted pendulum system include robustness in the presence of parameter uncertainties and disturbances plus ease of parameter selections for both the controller and observer.

\section{Conclusion}

This work presents some aspects regarding modelling and control of some robotics rotational experiments: flexible beam and inverted pendulum experiments. The experiments were realised using WinCon ${ }^{\mathrm{TM}}$ application that allows running code generated from a Simulink diagram in real-time. For the model describing the flexible beam experiment the control goal was to achieve the flexible beam position control and to damp the arm vibrations. The inverted pendulum experiment objective was to design a feedback control system that positions the arm as well as maintains the inverted pendulum vertical. Both experiments are highly nonlinear and consequently, the real mathematical models of the systems are very complicated, so for control purpose simplified models were used. Using the formulas of the kinetic and potential energies, from the generalized dynamic equations one obtained approximated linear models expressed by ordinary differential equations. Nonlinear systems model imprecision compensation and perturbations rejection were achieved using the robust controllers design. The LQG/LTR method was used in order to obtain feedback controllers for the benchmark robotic experiments. The aim of these controllers is to achieve robust stability margins and good performance in step response of the system. LQG/LTR method is a systematic design approach based on shaping and recovering open-loop singular values. The control strategies required the use of all state variables. Many of the proposed control strategies suppose that the state variables are available; this fact is not always true in practice so, it was necessary to design a state observer. The LQG/LTR control method and the modified Utkin SMO were designed and implemented. Sliding mode observers differ from more traditional observers e.g. Luenberger observers, in that there is a non-linear discontinuous term injected into the observer depending on the output estimation error. These observers are much more robust than Luenberger observers, as the discontinuous term enables the observer to reject disturbances. The Lyapunov based SMO (the so-called Walcott-Zak observer) provides exact estimation for certain class of nonlinear systems under existence of certain class of uncertainties. The difficulty in finding the design and gain matrices is the main drawback of this observer. A negative output feedback term was added to each equation of the Utkin observer and this result in a new error system. The addition of a Luenberger type gain matrix, feeding back the output error, yields the potential to provide robustness against certain classes of uncertainty. The problem considered was that of reconstructing the state variables using only measured output information.

For the flexible beam experiment a LQG/LTR controller was developed in order to achieve the flexible link position control and to damp the arm vibrations. The LQG/LTR controller uses the state estimations from a sliding-mode observer. A lot of experiments using the Quanser rotational experiments show that the modified Utkin sliding-mode observer provides better results than the classical Utkin sliding-mode observer. The results show also good angle reference tracking and vibration suppression. For the inverted pendulum experiment a LQG/LTR controller was developed also in order to maintain it upright. The non-measurable state variables are obtained using the modified Utkin SMO. The robustness of the controller is tested to some perturbations. The efficiency of the control-observer 
structure scheme has been successfully verified using the two experimental platforms. The proposed sliding mode observer-based control demonstrated very good performance; especially it is robust under external disturbances and it has good tracking references.

\section{Acknowledgment}

This work was supported by the National University Research Council - CNCSIS, Romania, under the research projects ID 786, 358/2007 (PNCDI II), and by the National Authority for Scientific Research, Romania, under the research projects SICOTIR, 05D7/2007 (PNCDI II).

\section{References}

Apkarian, J. (1997). A Comprenhensive and Modular Laboratory for Control Systems Design and Implementation, Quanser Consulting.

Athans, M. (1986). A tutorial on the LQG/LTR method. In Proc. American Control Conf, Seattle, WA, pp. 1289-1296, 1986.

Drakunov, S.V. \& Ozguner, U. (1992). Vibration suppression in Flexible Structures via the Sliding-Mode Control Approach, Proc. of 31st Conf. On Decision and Control, Tucson, USA, pp. 1365-1366, 1992.

Edwards, C. \& Spurgeon, S. K. (1994). On the development of discontinuous observers, Int. J. Control, vol. 59, no. 5, pp. 1211-1229.

Gauthier, J. P., Hammouri, H. \& Othman, S. (1992). A Simple Observer for Nonlinear Systems. Applications to Bioreactors, IEEE Trans. on Automatic Control, vol. 37, no. 6, pp. 875-880.

Gevers, M. \& Bastin, G. (1986). A Stable Adaptive Observer for a Class of Nonlinear SecondOrder Systems, in Analysis and Optimization of Systems, Bensoussan and Lions, Eds. New-York Springer-Verlag, pp. 143-155.

Gosavi S.V. \& Kelkar, A.G. (2001). Passivity-based Robust Control of Piezo-actuated Flexible Beam, Proc. of American Control Conference, Arlington, USA, pp. 2492-2497, June 25-27, 2001.

Gu, H. \& Song, G. (2004). Adaptive robust sliding-mode control of a flexible beam using PZT sensor and actuator, Proc. of 2004 IEEE Int. Symposium on Intelligent Control, Taipei, Taiwan, pp. 78-83, 2004.

Ionete, C. (2003). LQG/LTR Controller Design for Flexible Link Quanser Real-time Experiment, Proc. of Int. Symp. SINTES11, Craiova, Romania, vol. 1, pp. 49-54, 2003.

Jalili, N., Elmali, H., Moura, J.T. \& Olgac, N. (1997). Tracking Control of a Rotating Flexible Beam using Modified Frequency-shaped Sliding Mode Control, Proc. of American Control Conference, Albuquerque, USA, pp. 2552-2556, 1997.

Kalman, R.E. (1976). On a New Approach to Filtering and Prediction Problems, ASME J. Basic Engineering, Vol. 24, pp. 705-718.

Selişteanu, D., Sendrescu, D. \& Ionete, C. (2006). On Sliding Mode Control and Identification of a Flexible Beam, 12th IEEE International Conference on Method and Models in Automation and Robotics MMAR 2006, pp. 55-61, ISBN 83-60140-88-X , Miedzyzdroje, Poland, August 28-31, 2006.

Tan, C.P. \& Edwards, C. (2000). An LMI Approach for Designing Sliding Mode Observers, IEEE Conference on Decision and Control, Australia, pp.2587-2592, 2000. 
Thein, L.M-W. \& Misawa, E. A. (1995). Comparison of the Sliding Observer to Several State Estimators Using a Rotational Inverted Pendulum, Proc. of the 34th Conference on Decision and Control, New Orleans, pp. 3385-3390, 1995.

Utkin, V.I. (1992). Sliding Modes in Control Optimization. Berlin: Springer Verlag.

Walcott, B. L. \& Zak, S. H. (1986). Observation of dynamical systems in the presence of bounded nonlinearities/ uncertainties, Proc. of the 25th Conference on Decision and Control, pp. 961-966, 1986.

Xiong, Y. \& Saif, M. (2000). Sliding-mode Observer for Uncertain Systems. Part I: Linear Systems Case, Proc. of the 39th IEEE Conference on Decision and Control, Sydney, pp. 316-321, 2000. 


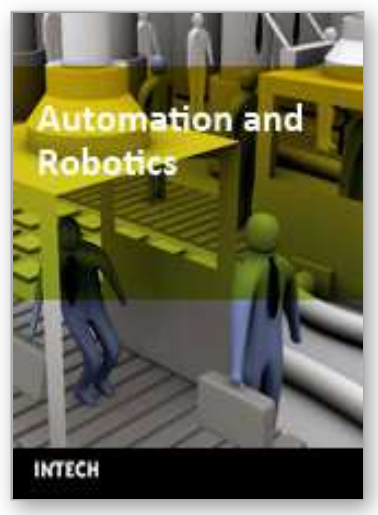

\author{
Automation and Robotics \\ Edited by Juan Manuel Ramos Arreguin
}

ISBN 978-3-902613-41-7

Hard cover, 388 pages

Publisher I-Tech Education and Publishing

Published online 01, May, 2008

Published in print edition May, 2008

In this book, a set of relevant, updated and selected papers in the field of automation and robotics are presented. These papers describe projects where topics of artificial intelligence, modeling and simulation process, target tracking algorithms, kinematic constraints of the closed loops, non-linear control, are used in advanced and recent research.

\title{
How to reference
}

In order to correctly reference this scholarly work, feel free to copy and paste the following:

Dorin Sendrescu, Dan Selisteanu, Emil Petre and Cosmin lonete (2008). Sliding Mode Observers for Rotational Robotics Structures, Automation and Robotics, Juan Manuel Ramos Arreguin (Ed.), ISBN: 978-3902613-41-7, InTech, Available from:

http://www.intechopen.com/books/automation_and_robotics/sliding_mode_observers_for_rotational_robotics_ structures

\section{INTECH}

open science | open minds

\section{InTech Europe}

University Campus STeP Ri

Slavka Krautzeka 83/A

51000 Rijeka, Croatia

Phone: +385 (51) 770447

Fax: +385 (51) 686166

www.intechopen.com

\section{InTech China}

Unit 405, Office Block, Hotel Equatorial Shanghai

No.65, Yan An Road (West), Shanghai, 200040, China

中国上海市延安西路65号上海国际贵都大饭店办公楼 405 单元

Phone: +86-21-62489820

Fax: $+86-21-62489821$ 
(C) 2008 The Author(s). Licensee IntechOpen. This chapter is distributed under the terms of the Creative Commons Attribution-NonCommercialShareAlike-3.0 License, which permits use, distribution and reproduction for non-commercial purposes, provided the original is properly cited and derivative works building on this content are distributed under the same license. 